\title{
Intrathecally adminis- tered NMDA receptor antagonists reduce the MAC of isoflurane in rats
}

Keiji Ishizaki MD, Nagahide Yoshida MD, Duck Mi Yoon MD, Myung-Ha Yoon MD, Makoto Sudoh MD, Tatsushi Fujita MD PhD
Purpose: We studied the effects of intrathecal administration of an N-methyl-D-aspartate (NMDA) receptor antagonist and an antagonist of the glycine site of the NMDA receptor on the minimum alveolar anaesthetic concentration (MAC) of isoflurane in rats, and on locomotor activity in conscious rats.

Methods: In Wistar rats fitted with indwelling intrathecal catheters, we determined the MAC of isoflurane after the administration of saline (control group); the competitive NMDA receptor antagonist 3-(2-carboxypiperazin-4-yl)propyl-1-phosponic acid(CPP) at 0.01,0.1, and 1.0 nM; and the selective antagonist of the glycine site on the NMDA receptor complex 7-chlorokynurenic acid (7CKA) at 0.1, 1.0, and 10 $n M$. After measurement of MAC following administration of the antagonist, the equipotent reversal dose of NMDA or $D$-serine was administered. The rats were examined for the presence of locomotor dysfunction by intrathecal administration of NMDA receptor antagonists, NMDA and D-serine in conscious rats. All of the experiments were performed using randomization and masking of drugs.

Results: CPP at 0.1 and $1.0 \mathrm{nM}$ decreased the MAC of isoflurane by $9.9-17.6 \%(P<0.05)$. 7CKA at 1.0 and $10 \mathrm{nM}$ reduced $M A C$ from $10.5-15.5 \%(P<0.05)$. Intrathecal administration of NMDA or D-serine reversed the decreases in $M A C$ to control values. Locomotor activity was not changed.

\section{Key words}

ANAESTHETICS, VOLATILE: isoflurane, MAC; NMDA RECEPTOR ANTAGONIST: CPP, 7CKA, intrathecal administration.

From the Department of Anesthesiology and Reanimatology, School of Medicine, Gunma University.

Address correspondence to: Dr. K. Ishizaki, Department of Anesthesiology and Reanimatology, School of Medicine, Gunma University, 3-39-22 Shouwamathi, Maebashi 371, Japan.

Accepted for publication 6th March, 1996.
Conclusions: We believe that NMDA receptor plays an important role in determining the MAC of isoflurane in the spinal cord.

Objectif: Étudier l'influence de l'administration d'un antagoniste du récepteur $N$-méthyl-D-aspartate (NMDA) et d'un antagoniste du site glycine du NMDA sur la concentration anesthésique alvéolaire minimum (MAC) de l'isoflurane chez le rat anesthésié et sur l'activité locomotrice chez le rat conscient.

Méthodes: Chez des rats Wistar porteurs d'un cathéter sousarachnoüdien implantés, nous avons déterminé le MAC après l'administration de soluté physiologique (groupe contrôle); de l'antagoniste compétitif du récepteur NMDA. l'acide 3-(2-carboxyperazine-4-yl)propyl-1-phosphonique (CPP) à 0,01,0,1 et 1,0 nM; et l'antagoniste sélectif du site glycine du complexe récepteur NMDA l'acide 7-chlorokynurénique (7CKA) à 0,1 1,0 et 10 nM. Après la mesure du MAC à la suite de l'administration de l'antagoniste, des doses de neutralisation équipotentes de NMDA ou de D-sérine ont été administrées. La présence d'un dysfonctionnement locomoteur a été recherchée par l'administration sous-arachoïdienne de l'antagoniste du récepteur NMDA, de NMDA et de D-sérine chez les rats conscients. Toutes les expériences ont été conduites aléatoirement et avec masquage des produits.

Résultats: Le CPP à 0,1 et 1,0 nM a diminué le MAC de l'isoflurane de 9,9-17.6\% $(P<0,05)$. Le 7CKA à 1,0 et $10 \mathrm{nM}$ a réduit le $M A C$ de $10,5-15,5 \%(P<0,05)$. Administration sous-arachnoiddienne de NMDA ou de D-sérine a ramené le MAC aux valeurs de contrôle. L'activité locomotrice n'a pas changé.

Conclusion: Nous croyons que le récepteur NMDA joue au niveau de la moelle épinière un rôle important dans la délimination du MAC.

More than $150 \mathrm{yr}$ after the introduction of anaesthesia into clinical practice, the mechanisms and sites of action are unknown. Traditionally, we have believed the brain 
to be a likely target site, specifically the cerebral cortex. With anaesthesia, we attempt to block consciousness, pain perception and memory functions associated with supraspinal, areas of the central nervous system. Accordingly, many experiments have been directed toward the assessment of anaesthetic effects on the cerebral cortex. Because of its presumed role in memory formation and attentiveness, the hippocampus has been the focus of recent studies. ${ }^{1}$ However, we know that inhalational anaesthetics exert considerable effects elsewhere, such as at the spinal cord. ${ }^{2,3}$ Anaesthetic agents at sufficient concentrations depress excitatory transmission in the spinal cord. A recent study in which the spinal cords of rats were transected without altering MAC suggested that the relevant site for MAC determination was in the spinal cord. ${ }^{4}$ Rampil et al. ${ }^{5}$ reported that MAC in rats was unchanged after precollicular decerebration. Antognini et al. ${ }^{6}$ reported that anaesthesia, as defined by MAC, was not determined by the cortex. Both reports support the hypothesis that the potency of anaesthetics is determined by their actions in the midbrain, the brain stem, or the lower spinal cord. The latter plays an important role in determining MAC.as defined in terms of motor response to a,noxious stimulus, most commonly a flexion withdrawal reflex, mediated at the spinal cord. ?

. The role of excitatory amino acids (EAAs) in nociception is suggested by the fact that noxious stimuli cause the release of glutamate and aspartate in the spinal cord dorsal horn. ${ }^{8,9}$ The EAAs act as transmitters in the spinal cord, especially in the superficial part of the dorsal horn.Intrathecal administration of.NMDA produces rapid, transient, dose-dependent hyperalgesia. ${ }^{10}$ This hyperalgesia is blocked by previous treatment with a selective NMDA receptor antagonist. ${ }^{11}$ It has also been shown that the release of peptides and an amino acid neurotransmitter from primary afferents is not suppressed by inhalation anaesthetics. ${ }^{12,13}$

A recent study has shown that the systemic administration of NMDA antagonists reduces the MAC of isoflurane. ${ }^{14}$ In contrast, glycine potentiates the NMDA receptor ion channel complex, ${ }^{15}$ and antagonism at the glycine site on the NMDA receptor produced an antinociceptive action. ${ }^{16}$

We reported that intrathecal administration of the competitive NMDA receptor antagonist APV (D-2amino-5-phosphopentaoate) and noncompetitive antagonist MK801(dizocilpine) reduced the MAC of isoflurane. ${ }^{17}$ However, the intrathecal administration of NMDA receptor antagonists may produce a sedative effect. The first purpose of this study was to investigate the effect of intrathecal administration of the NMDA receptor antagonist $\mathrm{CPP}$ and the selective antagonist of the glycine site on the NMDA receptor complex 7CKA on the MAC of isoflurane. The second was to examine the effect on the locomotor activity in conscious rats.

\section{Methods}

This investigation was conducted in accordance with a protocol approved by the Animal Care Committee of Gunma University. All of the experiments were performed using randomization and masking of drugs.

\section{Animal preparation}

Male Wistar rats $(280-320 \mathrm{~g})$ were fitted with indwelling intrathecal catheters using methods described previously. ${ }^{18}$ In brief, the rats were mounted in a conventional stereotaxic instrument under halothane anaesthesia. A middline incision was made on the skull, extending from a line between the ears to a point $2 \mathrm{~cm}$ caudal, and the fascia and muscle were retracted from the skull and first vertebra. The atlanto-occipital membrane could be seen easily. When the incision was made correctly, there was a copious outwelling of clear cerebrospinal fluid. The indwelling intrathecal catheters were placed by passing a PE-10 catheter through an incision in the atlanto-occipital membrane to a position $8 \mathrm{~cm}$ caudal to the cisterna at the level of the lumbar enlargement. The catheter was externalized on the top of the skull, and the wound was closed with 3-0 silk sutures. We used only catheterized rats in which flaccid paralysis of the hindlimbs was observed after intrathecal administration of lidocaine $500 \mu \mathrm{g} \cdot 10 \mu \mathrm{l}^{-1,19}$ on the day of surgery. Rats showing postoperative. neurological deficits, inflammation and weight loss were killed with a barbiturate overdose. Measurement of the MAC was carried out four to nine days after the intrathecal implantation of the catheter.

The agents studied were CPP (3-(2-carboxypiperazin-4-yl)propyl-1-phosphonic acid, Research Biochemical Inc), 7CKA (7-chlorokynurenic acid, Sigma), NMDA (N-methyl-D-aspartate, Sigma); and D-serine (2-amino-3hydropropanic acid; $\beta$-hydroxylamine, Sigma). All drugs were dissolved in normal saline, so that the final dose was administered in a volume of $10 \mu \mathrm{l}$. The animals were allocated randomly to eleven groups with six animals per group by a person who did not know the experimental protocol, including one control group and six NMDA antagonist groups; three groups received CPP 0.01-1 $\mathrm{nM}$, and three groups received 7CKA 0.1-10 nM. After measurement of the MAC following administration of the antagonist, the equipotent reversal dose of NMDA $0.01-1 \mathrm{nM}$ or D-serine 0.1-10 $\mathrm{nM}$ was administered regardless of whether MAC 
decreased. In another two groups, NMDA receptor antagonists CPP $0.1 \mathrm{nM}$ and 7CKA $1 \mathrm{nM}$ were reversed by various concentration of NMDA and D-serine, respectively. In the other two groups, rats with administered saline were treated with various concentration of NMDA and D-serine.

\section{Measurement of MAC}

Anaesthesia was induced with halothane $4 \%$ in oxygen by placing the rats in an induction chamber for three to five minutes. After tracheostomy, the trachea of each animal was intubated with a $14-G$ polyethylene catheter. The rats breathed spontaneously through a non-rebreathing circuit. The oxygen supply to the isoflurane vaporizer was kept at $2 \mathrm{~L} \cdot \mathrm{min}^{-1}$ throughout the experiments. A polyethylene catheter (PE50) was inserted through the wall of the ventilatory tubing, and the tip of the sampling tube was positioned distal to the tracheostomy; this arrangement permitted sampling of end-tidal gases and regulation of end-tidal $\mathrm{CO}_{2}$ by management of the oxygen escape valve. For blood pressure monitoring and blood sampling, one femoral artery was catheterized with a polyethylene catheter (PE50). Rectal temperature was maintained between 36.5 and $37.5^{\circ} \mathrm{C}$ by use of a heating pad and thermometer system (CMA150, Microdialysis AB, Stockholm, Sweden). The end-tidal concentration of isoflurane was measured with a calibrated infrared absorption instrument (ULTIMA, Datex Co., Helsinki, Finland). ${ }^{20}$ The analyzer was warmed up for at least $90 \mathrm{~min}$ before use and was calibrated with a standard calibration gas mixture.

The MAC of isoflurane was determined according to the up-and-down method using of the tail clamp technique. $^{7}$ After surgery, in each animal the lungs were ventilated initially for $20 \mathrm{~min}$ with isoflurane $1.5 \%$. First, we injected saline to measure the standard MAC. A 20-cm rubber-shod haemostat was then applied with full ratcheted lock to the mid-portion of the rat's tail. The haemostat was applied continuously for $60 \mathrm{sec}$ and then was removed. Any purposeful movement of the animal constituted a positive response, such as the movement of extremities, tail flick, or twitching. Nonpurposeful movements, such as stiffening, grimacing, and changing of respiratory patterns were disregarded. The isoflurane concentration was then adjusted by $10 \%$, and drug was administered for $20 \mathrm{~min}$ at the new concentration before application of the haemostat was repeated. The subsequent position of the tail clamp was proximal to any previous site of application. The MAC was defined as the mean of the lowest concentration at which a negative response was observed plus the highest concentration at which a positive response was observed. After measurement of control values, CPP and 7CKA were infused intrathecally by the investigator who was blind to the drug used in the infusion. When the measurement of MAC of the NMDA receptor antagonists was completed, NMDA or D-serine was administered intrathecally. We performed a blood gas sample just before tail clamp.

\section{Test of locomotor function}

The rats were examined for the presence of locomotor dysfunction using the following methods. ${ }^{21}$ The NMDA receptor antagonists, NMDA and D-serine, were injected in the manner described above in 13 groups of five rats each. The experimenter did not know which drug was injected and the following tests were performed:

1 Placing reflex: The rat was held with the hindlimbs slightly lower than the forelimbs, and the dorsal surface of the hindpaws was brought into contact with the edge of a table. The experimenter recorded whether the hindpaws were placed on the table surface reflexively;

2 Grasping reflex: The rat was placed on a wire grid and the experimenter recorded whether the hindpaws grasped the wire upon contact;

3 Righting reflex: The rat was placed on its back on a flat surface and the experimenter noted whether it immediately assumed the normal upright position. Scores for placing, grasping and righting reflexes were based on counts of each normal reflex exhibited in five trials.

\section{Statistical analysis}

Statistical comparisons were made by ANOVA, and the Bonferroni method was applied for multiple comparisons. Wilcoxon's signed rank sum test was performed on the MAC values within each group. The level of statistical significance was defined as $P<0.05$. The values are expressed as mean \pm SEM.

\section{Results}

The physiological variables were well controlled: there were no differences among the group (Tables I, II). Body temperature remained unchanged during the experiment. Tables III and IV show the changes in the MAC of isoflurane. There were no differences among the seven groups with respect to baseline MAC values. At a CPP dose of $0.01 \mathrm{nM}$, three of six rats showed a decrease in MAC; at CPP doses $0.1 \mathrm{nM}$ and $1.0 \mathrm{nM}$, all of the rats had a decrease in the MAC. At $0.1 \mathrm{nM}$ and $1.0 \mathrm{nM}, \mathrm{CPP}$ produced decreases in the MAC of isoflurane ranging from $9.9-17.6 \%$ of control values $(P<$ 0.05 ). Administration of NMDA reversed the decreases 
TABLE I Mlean (SEM) changes in physiological variables due to intrathecal administration of CPP and NMDA

\begin{tabular}{|c|c|c|c|c|c|c|c|}
\hline & \multirow{2}{*}{$\begin{array}{l}\text { Saline } \\
n=6\end{array}$} & $C P P 0.01 n M$ & $N M D A 0.01 \mathrm{nM}$ & $C P P 0.1 n M$ & $N M D A 0.1 n M$ & $C P P \ln M$ & $N M D A / n M$ \\
\hline & & \multicolumn{2}{|c|}{$n=6$} & \multicolumn{2}{|c|}{$n=6$} & \multicolumn{2}{|c|}{$n=6$} \\
\hline MAP (mmHg) & $108(5)$ & $111(8)$ & $114(4)$ & $105(9)$ & $114(8)$ & $104(4)$ & $117(7)$ \\
\hline Heart rate (bpm) & $353(22)$ & $373(9)$ & $387(30)$ & $380(9)$ & $417(14)$ & $364(12)$ & $415(14)$ \\
\hline $\mathrm{PaO}_{2}(\mathrm{mmHg})$ & $380(20)$ & $322(28)$ & $372(22)$ & $360(17)$ & $392(33)$ & $382(28)$ & $395(25)$ \\
\hline $\mathrm{PaCO}_{2}(\mathrm{mmHg})$ & $37.5(0.9)$ & $38.9(1.4)$ & $38.4(0.5)$ & $38.0(0.0)$ & $38.7(1.2)$ & $38.3(0.9)$ & $37.2(0.9)$ \\
\hline $\mathrm{pH}$ & $7.40(0.02)$ & $7.40(0.02)$ & $7.41(0.02)$ & $7.39(0.01)$ & $7.39(0.01)$ & $7.43(0.01)$ & $7.40(0.01)$ \\
\hline $\mathrm{HCO}_{3}^{-}\left(\right.$meq $\left.\cdot \mathrm{L}^{-1}\right)$ & $23.5(0.5)$ & $23.1(0.7)$ & $23.1(0.7)$ & $23.2(0.8)$ & $23.3(0.7)$ & $23.1(0.7)$ & $23.3(0.8)$ \\
\hline Body temperature $\left({ }^{\circ} \mathrm{C}\right)$ & $37.1(0.1)$ & $37.0(0.1)$ & $37.0(0.1)$ & $37.0(0.2)$ & $37.0(0.2)$ & $36.9(0.2)$ & $36.9(0.1)$ \\
\hline $\mathrm{Hb}\left(\mathrm{g} \cdot \mathrm{dl}^{-1}\right)$ & $13.6(0.4)$ & $14.0(0.5)$ & $13.8(0.7)$ & $13.9(0.5)$ & $13.9(0.5)$ & $14.4(0.3)$ & $13.9(0.4)$ \\
\hline
\end{tabular}

TABLE II Mean (SEM) changes in physiological variables due to intrathecal administration of 7CKA and D-serine

\begin{tabular}{|c|c|c|c|c|c|c|c|}
\hline & \multirow{2}{*}{$\begin{array}{l}\text { Saline } \\
n=6\end{array}$} & $7 C K A 0.1 \mathrm{nM}$ & D-serine $0.1 \mathrm{nM}$ & $7 C K A 1 n M$ & D-serine I $n M$ & $7 C K A 10 \mathrm{nM}$ & D-serine $10 \mathrm{nM}$ \\
\hline & & \multicolumn{2}{|c|}{$n=6$} & \multicolumn{2}{|c|}{$n=6$} & \multicolumn{2}{|c|}{$n=6$} \\
\hline MAP (mmHg) & $108(5)$ & $115(5)$ & $112(8)$ & $116(5)$ & $118(5)$ & $116(7)$ & $118(6)$ \\
\hline Heart rate (bprn) & $353(22)$ & $365(7)$ & $368(13)$ & $359(9)$ & $387(15)$ & $391(20)$ & $372(18)$ \\
\hline $\mathrm{PaO}_{2}(\mathrm{mmHg})$ & $389(20)$ & $406(22)$ & $405(27)$ & $319(40)$ & $379(20)$ & $404(10)$ & $371(15)$ \\
\hline $\mathrm{PaCO}_{2}(\mathrm{mmHg})$ & $37.5(0.9)$ & $37.5(0.8)$ & $36.9(0.5)$ & $37.5(0.5)$ & $37.6(0.7)$ & $37.6(0.8)$ & $37.9(1.8)$ \\
\hline $\mathrm{pH}$ & $7.40(0.02)$ & $7.42(0.01)$ & $7.41(0.01)$ & $7.41(0.01)$ & $7.40(0.01)$ & $7.41(0.01)$ & $7.40(0.01)$ \\
\hline $\mathrm{HCO}_{3}^{-}\left(\mathrm{meq} \cdot \mathrm{L}^{-1}\right)$ & $23.5(0.5)$ & $23.1(0.6)$ & $23.4(0.7)$ & $23.2(0.6)$ & $23.1(0.6)$ & $23.3(0.8)$ & $23.4(0.9)$ \\
\hline Body temperature $\left({ }^{\circ} \mathrm{C}\right)$ & $37.1(0.1)$ & $37.0(0.1)$ & $36.9(0.1)$ & $37.1(0.2)$ & $37.1(0.1)$ & $37.0(0.1)$ & $36.9(0.2)$ \\
\hline $\mathrm{Hb}\left(\mathrm{g} \cdot \mathrm{dl}^{-1}\right)$ & $13.6(0.4)$ & $13.8(0.5)$ & $14.5(0.3)$ & $13.4(0.8)$ & $13.5(0.5)$ & $14.4(0.2)$ & $14.4(0.5)$ \\
\hline
\end{tabular}

TABLE III Mean (SEM) changes in MAC of isoflurane caused by intrathecal administration of saline, CPP and NMDA. $n=6$

\begin{tabular}{lll}
\hline $\begin{array}{l}\text { Saline } \\
1.43(0.02)\end{array}$ & $\begin{array}{l}\text { Saline } \\
1.43(0.02)\end{array}$ & $\begin{array}{l}\text { Saline } \\
1.43(0.02)\end{array}$ \\
\hline Saline & CPP 0.01 nM & $\begin{array}{l}\text { NMDA 0.01 nM } \\
1.42(0.02)\end{array}$ \\
\hline $1.43(0.02)$ & $1.39(0.02)$ & NMDA 0.1nM \\
Saline & CPP 0.1nM & $1.38(1.03)^{b}$ \\
$1.42(0.03)^{a}$ & $1.28(0.02)^{a, b}$ & NMDA 1 nM \\
\hline Saline & CPP 1nM & $1.39(0.03)^{b}$ \\
$1.43(0.02)^{a}$ & $1.17(0.02)^{a, b}$ & \\
\hline
\end{tabular}

${ }^{a}$ Saline vs CPP. $(P<0.05)$.

${ }^{b}$ CPP vs NMDA $(P<0.05)$.

in the MAC of isoflurane (Table III). Two of six rats showed a decrease in MAC at a dose of $0.1 \mathrm{nM}, 7 \mathrm{CKA}$. When given at $1.0 \mathrm{nM}$ and $10 \mathrm{nM}, 7 \mathrm{CKA}$ caused MAC to decrease $10.5-15.5 \%$ of control values $(P<0.05)$. Intrathecal administration of $D$-serine reversed the decreases in MAC (Table IV). Reversal effects of NMDA occurred at a CPP dose $0.1 \mathrm{nM}$ and of D-serine at a 7CKA dose $1.0 \mathrm{nM}$ (Table V, VI). NMDA and $\mathrm{D}$-serine did not increase the MAC of isoflurane. There were no differences between groups of the effects of the agents on locomotor function (Table VII). Convulsions
TABLE IV Mean (SEM) changes in MAC of isoflurane caused by intrathecal administration of 7CKA and D-serine $n=6$

\begin{tabular}{|c|c|c|}
\hline $\begin{array}{l}\text { Saline } \\
1.44(0.03)\end{array}$ & $\begin{array}{l}\text { 7CKA } 0.1 \mathrm{nM} \\
1.41(0.02)\end{array}$ & $\begin{array}{l}\text { D-serine } 0.1 \mathrm{nM} \\
1.43(0.02)\end{array}$ \\
\hline $\begin{array}{l}\text { Saline } \\
1.43(0.02)^{a}\end{array}$ & $\begin{array}{l}7 \text { CKA } 1.0 \mathrm{nM} \\
1.28(0.02)^{a, b}\end{array}$ & $\begin{array}{l}\text { D-serine } 1.0 \mathrm{nM} \\
1.38(0.03)^{b}\end{array}$ \\
\hline $\begin{array}{l}\text { Saline } \\
1.42(0.03)^{a}\end{array}$ & $\begin{array}{l}7 \text { CKA } 10 \mathrm{nM} \\
1.20(0.03)^{a, b}\end{array}$ & $\begin{array}{l}\text { D-serine } 10 \mathrm{nM} \\
1.42(0.03)^{b}\end{array}$ \\
\hline
\end{tabular}

and hypermobility were not observed in association with $\mathrm{CPP}+\mathrm{NMDA}$ or $7 \mathrm{CKA}+\mathrm{D}$-serine.

\section{Discussion}

Physiological variables were well controlled, and body temperature remained stable. We regulated the $\mathrm{PaCO}_{2}$ by managing the escape flow; $\mathrm{PaCO}_{2}$ did not change during the experiment. There were no factors that influenced the MAC of isoflurane other than the NMDA receptor antagonists. ${ }^{22}$ Administration of an NMDA receptor antagonist and an antagonist of the glycine site decreased the MAC of isoflurane, but this was reversed by the administration of NMDA and D-serine. It has been proposed that the NMDA receptor is related to the 
TABLE V Mean (SEM) changes in MAC caused by various concentration of NMDA at saline and CPP, $0.1 \mathrm{nM} . n=6$

\begin{tabular}{llll}
\hline & \multicolumn{3}{l}{ Saline } \\
\cline { 2 - 4 } Saline & NMDA 0.01 nM & NMDA 0.1 nM & NMDA 1 nM \\
\hline $1.43(0.03)$ & $1.44(0.03)$ & $1.45(0.03)$ & $1.48(0.04)$ \\
\hline & CPP 0.1nM & & \\
\cline { 2 - 4 } CPP 0.1nM & NMDA 0.01 nM & NMDA 0.1 nM & NMDA I nM \\
\hline $1.28(0.02)^{a}$ & $1.32(0.02)$ & $1.38(0.03)^{a}$ & $1.42(0.03)^{a}$ \\
\hline
\end{tabular}

${ }^{a} \mathrm{CPP} 0.1 \mathrm{nM}$ vs CPP $0.1 \mathrm{nM}+\mathrm{NMDA} 0.1 \mathrm{nM}$ and CPP $0.1 \mathrm{nM+}$ NMDA $1 \mathrm{nM}(P<0.05)$.

TABLE VI Mean (SEM) changes in MAC caused by various concentration of D-serine at saline and 7CKA, 1 nM. $n=6$

\begin{tabular}{llll}
\hline \multirow{3}{*}{ Saline } & \multicolumn{3}{l}{ Saline } \\
\cline { 2 - 4 } & D-serine 0.I nM & $D$-serine I nM & D-serine 10 $\mathrm{nM}$ \\
\hline $1.42(0.02)$ & $1.44(0.03)$ & $1.45(0.03)$ & $1.47(0.04)$ \\
\hline & $7 C K A$ InM & & \\
\cline { 2 - 4 } 7CKA InM & D-serine 0.I nM & $D$-serine I nM & D-serine 10 $\mathrm{nM}$ \\
\hline $1.28(0.02)^{a}$ & $1.30(0.02)$ & $1.39(0.03)^{a}$ & $1.43(0.03)^{a}$ \\
\hline
\end{tabular}

a 7CKA $1 \mathrm{nM}$ vs 7CKA $1 \mathrm{nM}+\mathrm{D}$-serie $1 \mathrm{nM}$ and $7 \mathrm{CKA} 1 \mathrm{nM}+$ D-serine $10 \mathrm{nM}(P<0.05)$

TABLE VII Mean (SEM) changes in locomotor test. $n=5.5$ trials

\begin{tabular}{llll}
\hline Drug & Placing & Grasping & Righting \\
\hline Saline & $5(0)$ & $5(0)$ & $5(0)$ \\
CPP 0.01 nM & $5(0)$ & $5(0)$ & $5(0)$ \\
CPP 0.1 nM & $5(0)$ & $5(0)$ & $5(0)$ \\
CPP 1.0 nM & $4.8(0.1)$ & $4.8(0.1)$ & $4.8(0.1)$ \\
& & & \\
7CKA 0.1 nM & $5(0)$ & $5(0)$ & $5(0)$ \\
7CKA 1.0 nM & $5(0)$ & $5(0)$ & $5(0)$ \\
7CKA 10 nM & $4.6(0.2)$ & $4.8(0.2)$ & $4.6(0.2)$ \\
& & & \\
CPP 0.01 nM+NMDA 0.01 nM & $5(0)$ & $5(0)$ & $5(0)$ \\
CPP 0.1 nM+NMDA 0.1 nM & $5(0)$ & $5(0)$ & $5(0)$ \\
CPP 1.0 nM+NMDA 1.0 nM & $5(0)$ & $5(0)$ & $5(0)$ \\
& & & \\
7CKA 0.1 nM+D-serine 0.1 nM & $5(0)$ & $5(0)$ & $5(0)$ \\
7CKA 1.0 nM+D-serine 1.0 nM & $5(0)$ & $5(0)$ & $5(0)$ \\
7CKA 10 nM+D-serine 10 $10 \mathrm{nM}$ & $5(0)$ & $5(0)$ & $5(0)$ \\
\hline
\end{tabular}

MAC of inhalation anaesthetics. ${ }^{14,17}$ The degree of reduction in MAC was similar to that obtained with intrathecal administration of the competitive NMDA receptor antagonist APV and noncompetitive antagonist MK801. ${ }^{17}$ The competitive NMDA receptor antagonist CPP directly blocks the glutamate recognition site and
CPP is a more potent NMDA receptor antagonist than APV. Kirstensen et al. ${ }^{23}$ reported that CPP had antinociceptive effects in three different nociceptive tests: a tail-flick, a hot-plate, and a formalin test. The action of glycine seems to be mediated via an allosteric recognition site on the NMDA receptor. It has been demonstrated that responses evoked by NMDA in cultured neurons can be potentiated by glycine..$^{15}$ Glycine modulates the NMDA system not only at the supraspinal level but also at the spinal level. ${ }^{24}$ The analgesic potential of glycine-allosteric antagonists is evidenced by the finding that a selective antagonist of the allosteric-glycine site (7CKA) reduces the wind-up of dorsal horn neurons following tissue injury induced by subcutaneous injection of formalin into a rat's hindpaw. ${ }^{16}$ The effect of 7CKA is completely reversible and preventable by D-serine. ${ }^{25}$ In this experiment, we chose doses that had an antinociceptive action without causing motor dysfunction when administered intrathecally in rats. ${ }^{21,23} \mathrm{We}$ believe that intrathecally administered NMDA receptor antagonists may act by inhibiting the binding site of the glutamate or aspartate that is released by primary afferents in the spinal dorsal horn. The NMDA receptor antagonist CPP disturbed the transmission and, thus, reduced the MAC of isoflurane. Administration of 7CKA decreased $A$ and $C$-fibre inputs and may reduce the consequences of NMDA events in sensory processing in the spinal cord. For this reason, antagonists of the glycine site on the NMDA receptor may reduce the MAC of isoflurane. Competitive NMDA receptor antagonists are slowly hydrophilically redistributed from the injection site. ${ }^{26}$ In contrast, 7CKA is a highly lipophilic drug that is redistributed rapidly from the spinal cord to the peripheral nerves. ${ }^{21}$ The doses of 7CKA required to reduce the MAC of isoflurane were larger than those of CPP.

Intrathecal administration in a rat model is common. However, there are many problems with the use of this model. We excluded rats with nerve injury, inflammation and weight loss after insertion of the catheter. The MAC was influenced by these events. We measured body weight and monitored inflammation in the suture region and MAC was stable on days four to nine. We used only catheterized rats in which flaccid paralysis of the hindlimbs was observed just after intrathecal administration of lidocaine $500 \mu \mathrm{g} \cdot 10 \mu \mathrm{l}^{-1}$ on the day of surgery. ${ }^{19}$ It is important to place the catheter correctly. When the catheter tip was in a good position, we were able to see the paralysis just after injection. If the drug was injected into the epidural space, paralysis was observed $20 \mathrm{~min}$ later.

The intrathecal administration of NMDA receptor antagonists may produce a sedative effect and MK801 
and APV cause ataxia, sedation and anaesthesia. ${ }^{26}$ Kurode et al: ${ }^{14}$ reported that systemical administration of NMDA. receptor antagonists decreases MAC of isoflurane by $50 \%$. According to this report, the investigators used neuroprotective doses of NMDA receptor antagonists. Administration of NMDA receptor antagonists at a dose of $17.8 \mathrm{mM} \cdot \mathrm{kg}^{-1}$ (one million times higher than our doses) produces some adverse effects, such as ataxia, perceptual disorders, sedation, anaesthesia, and psychotomimetic effects. We believe that the sedative effect decreased the MAC of isoflurane in previous experiments and therefore, used an antinociceptive dose without sedative effects in this study. The degree of reduction in the MAC was small compared with that obtained with systemical administration of neuroprotective doses.

Administration of NMDA receptor antagonists causes motor nerve dysfunction and CPP produces motor nerve dysfunction at a doses of $10 \mathrm{nM}^{23}$ Coderre et $a .^{21}$ reported that 7CKA also caused disruption of the placing reflex at a dose of $18 \mathrm{nM}$. Motor nerve paralysis produced by NMDA receptor antagonists could reflect an increase in extensor tone produced by a reduction in post-synaptic inhibition of motor neurons following antagonism of synaptic excitation of Renshaw cells or other interneurons. ${ }^{27}$ A locomotor test did not reveal motor weakness in our experiment.

When NMDA is administered intrathecally in the mouse, it elicits dose-related, caudally directed biting and scratching behaviour. However, this hyperalgesia is blocked by previous treatment with a selective NMDA receptor antagonist." "We injected NMDA following the administration of an NMDA receptor antagonist and did not observe convulsions or hypermobility.

There are some problems in using NMDA receptor antagonists in clinical practice. Competitive NMDA receptor antagonists such as CPP and APV do not easily cross the blood-brain barrier, so clinical administration is limited. Noncompetitive NMDA receptor antagonists such as ketamine and MK801 produce psychotomimetic effects at a higher dose levels. ${ }^{26}$ In contrast, antagonists of the glycine site of the NMDA receptor complex easily cross the blood-brain barrier and produce potent NMDA receptor antagonism at doses that do not produce neurotoxic or behaviour stimulant effects. ${ }^{21}$ Antagonists of the glycine site on the NMDA receptor complex may be used with a lowered risk of undesired side effects. The only NMDA receptor antagonist licensed for use in patients is the dissociative anaesthetic ketamine, which is unpleasant for most patients when given systemically. Nevertheless, epidural ketamine produces potent postoperative analgesia. ${ }^{28}$ Ketamine probably produces its analgesic effects by disrupting sensory input in the spinal cord and thalamus. ${ }^{29}$ There is evidence that wind-up is dependent on NMDA receptor activation $^{30}$ and that NMDA receptor antagonists may prevent behaviour indicative of pain. ${ }^{31}$. This experiment suggest a new possibility that NMDA receptor antagonists decrease the need for inhalational anaesthetics and reduce postoperative pain with no unacceptable side effects. Further investigation is necessary before NMDA receptor antagonists are accepted for clinical use.

In summary, the MAC of isoflurane is depressed by intrathecal administration of the competitive NMDA receptor antagonist $\mathrm{CPP}$ and the antagonist of the glycine site on the NMDA receptor 7CKA.

Intrathecal administration of NMDA or D-serine reversed the decreases in MAC to control values. Locomotion activity is not changed.

\section{References}

1 Kendig $J$, Maciver MB, Roth SH. Anesthetic actions in the hippocampal formation. Ann N Y Acad Sci1991; 625: 37-53.

2 Namiki A, Collins JG, Kitahata LM, Kikuchi H, Homma E, Thalhammer JG. Effects of halothane on spinal neuronal responses to graded noxious heat stimulation in the cat. Anesthesiology 1980; 53: 475-80.

3 de Jong RH, Robles R, Corbin RW, Nace RA. Effect of inhalation anesthetics on monosynaptic and polysynaptic transmission in the spinal cord. J Pharmacol Exp Ther 1968; 162: 326-30.

4 Rampil IJ. Is MAC testing a spinal reflex? Anesthesiology 1993; 79: A422.

5 Rampil IJ, Mason P, Singh H. Anesthetic potency (MAC) is independent of forebrain structures in the rat. Anesthesiology 1993; 78: 707-12.

6 Eger EI II, Saidman LJ, Brandstater B. Minimum alveolar anesthetic concentration: a standard of anesthetic potency. Anesthesiology 1965; 26: 756-63.

7 Antognini JF, Schwartz K. Exaggerated anesthetic requirements in the preferentially anesthetized brain. Anesthesiology 1993; 79: 1244-9.

8 Skilling SR; Smullin DH, Beitz AJ, Larson AA. Extracellular amino acid concentrations in the dorsal spinal cord of freely moving rats following veratridine and nociceptive stimulation. J Neurochem 1988; 51: 127-32.

9 Sorkin LS, Westlund KN, Sluka KA, Dougherty PM, Willis $W D$. Neural changes in acute arthritis in monkeys. IV. Time-course of amino acid release into the lumbar dorsal horn. Brain Res Rev.1992; 17: 39-50.

10 Schneider SP, Perl ER. Comparison of primary afferent and glutamate excitation of neurons in the mammalian spinal dorsal horn. J Neurosci 1988; 8: 2062-73.

11 Aanonsen $L M$, Wilcox $G L$. Nociceptive action of excitatory amino acids in the mouse: effects of spinally adminis- 
tered opioids, phencyclidine and sigma agonists. J

Pharmacol Exp Ther 1987; 243: 9-19.

12 Go VLW, Yaksh TL. Release of substance P from the cat spinal cord. J Physiol (Lond) 1987; 391: 141-67.

13 Heavner JE. Jamming spinal sensory input: effects of anesthetic and analgesic drugs in the spinal cord dorsal horn. Pain 1975; 1: 239-55.

14 Kuroda $Y$, Strebel S, Rafferty C, Bullock R. Neuroprotective doses of $\mathrm{N}$-Methyl-D-aspartate receptor antagonists profoundly reduce the minimum alveolar anesthetic concentration(MAC) for isoflurane in rats. Anesth Analg 1993; 77: 795-800.

15 Johnson JW, Ascher P. Glycine potentiates the NMDA response in culture mouse brain neurons. Nature 1987; 325: 529-31.

16 Dickenson AH, Aydar $E$. Antagonism at the glycine site on the NMDA receptor reduces spinal nociception in the rat. Neurosci Lett 1991; 121: 263-6.

17 Ishizaki K, Yoon DM, Yoshida N, Yamazaki M, Arai K, Fujita T. Intrathecal administration of N-methyl-D-aspartate receptor antagoist reduces the minimum alveolar anaesthetic concentration of isoflurane in rats. $\mathrm{Br} \mathrm{J}$ Anaesth 1995; 75: 636-8.

18 Yaksh TL, Rudy TA. Chronic catheterization of spinal subarachnoid space. Physiol Behav 1976; 17: 1031-6.

19 Penning JP, Yaksh TL. Interaction of intrathecal morphine with bupivacaine and lidocaine in the rat. Anesthesiology 1992; 77: 1186-200.

20 Colquhoun $A D$, Gray WM, Asbury AJ. An evaluation of the Datex Normac anaesthetic agent monitor. Anaesthesia 1986; 41: 198-204.

21 Coderre TJ, Van Empel 1. The utility of excitatory amino acid (EAA) antagonist as analgesic agents. I. Comparison of the antinociceptive activity of various classes of EAA antagonist in mechanical, thermal and chemical nociceptive tests. Pain 1994; 59: 345-52.

22 Quash AL, Eger EI II, Tinker JH. Determination and applications of MAC. Anesthesiology 1980; 53: 315-34.

23 Kristensen JD, Karlsten $R$, Gordh T, Berge O-G. The NMDA antagonist 3-(2- carboxypiperazin-4-yl) propyl-1phosponic acid (CPP) has antinociceptive effect after intrathecal injection in the rat. Pain 1994; 56: 59-67.

24 Brugger $F$, Wicki U, Nassenstein-Elton D, Fagg GE, Olpe $H \cdot R$, Pozza MF. Modulation of the NMDA receptor by $D$-serine in the cortex and the spinal cord, in vitro. Eur $\mathbf{J}$ Pharmacol 1990; 191: 29-38.

25 Birch PJ, Grossman CJ, Hayes AG. Kynurenic acid antagonises responses to NMDA via an action at the strychnineinsensitive glycine receptor. Eur J Pharmacol 1988; 154: 85-7.

26 Willetts J, Balster RL, Leander JD. The behavioral pharmacology of NMDA receptor antagonists. Trends Pharmacol Sci 1990; 11: 423-8.
27 Davies J, Evans RH, Francis AA, Jones AW, Watkins JC. Antagonism of excitatory amino acid-induced and synaptic excitation of spinal neurones by cis-2, 3-piperidine dicarboxylate. J Neurochem 1981; 36: 1305-7.

28 Naguib M, Sharif AMY, Seraj M, El Gammal M, Dawlatly $A A$. Ketamine for caudal analgesia in children: comparison with caudal bupivacaine. Br J Anaesth 1991; 67: 559-64.

29 White PF, Way WL, Trevor AJ. Ketamine - its pharmacology and therapeutic uses. Anesthesiology 1982; 56: 119-36.

30 Woolf CJ, Thompson SWN. The induction and maintenance of central sensitization is dependent on $\mathrm{N}$-methyl-D-aspartic acid receptor activation; implications for the treatment of post-injury pain hypersensitivity states. Pain 1991; 44: 293-9.

31 Yamamoto T, Yaksh TL. Comparison of the antinociceptive effects of pre-and posttreatment with intrathecal morphine and MK801, an NMDA antagonist, on the formalin test in the rat. Anesthesiology 1992; 77: 757-63. 